Session 2238

\title{
A New Approach to Teaching Engineering Graphics Using Active Learning and Product Realization
}

\author{
Mahmoud K. Ardebili ${ }^{1}$ and Ali M. Sadegh ${ }^{2}$, \\ 1-Engineering Science Program, Borough of Manhattan Community \\ College, New York \\ 2-Mechnical Engineering Department, the City College of New York, \\ New York
}

\begin{abstract}
Undergraduate engineering programs are modifying their curricula to incorporate various forms of active learning. This paper presents a modified engineering graphics course that is instructed in an active learning environment. The class teaches fundamentals of engineering graphics. It provides students with an opportunity to learn solid modeling as a tool for design process and product realization in addition to skills/competencies that traditional introductory graphics classes promote.
\end{abstract}

The main thrust of the new curriculum is on the project-based learning. It is believed that presenting the topics of the course through a project would expose the students to real engineering practice. In fact, this approach helps students, throughout their engineering programs, to prepare themselves for the Capstone Projects in the senior design courses. Specifically, students are given the opportunity to disassemble a real product and construct drawings of its parts. At the end of the course students are required to create a group poster presentation.

The syllabus includes learning cycles. Each cycle begins with classroom lectures to introduce the concept. This is reinforced by a hands-on laboratory "physical experience" to encourage student ownership of the concept. A recitation-style working session follows to provide practice with the tools available in using the concept. Homework assignments will provide practice. The cycle is culminated by a team-designed project requiring application of the concept in addition to other topics that have been covered.

Engineering Science in BMCC and Mechanical Engineering in CCNY use the course curriculum in their Fundamental of Engineering Graphic courses. Students have responded positively to the new curriculum. This is reflected by their assessment of class and the depth and rigor of their projects. They feel that the class is both a skill and technical one, which reinforces analytical geometry and vector skills. Faculty teaching the class have also responded positively to this approach and feel it is easier to instruct the class. 


\section{Introduction}

Engineering education is undergoing changes. Educators constantly reassess the content of engineering curricula in the context of emerging technologies. It is necessary to devise, implement and evaluate innovative pedagogical approaches into the educational programs without compromising the traditional skills promoted in the curriculum. Over the course of the last few years, project-based instruction has gained acceptance by the educational community and is now being applied in a wide range of engineering disciplines, at various types of academic institutions and throughout the different phases of the educational programs. This paper presents how the engineering graphics course at $\mathrm{CCNY}$ and $\mathrm{BMCC}$ was modified to be conducted in a project-based environment.

An ASME study [1] conducted among US industry gives an outlook on skills and areas of knowledge valued by senior-level mangers for a BS level mechanical engineer. These skills and areas of knowledge can be labeled together as product realization skills, see table 1. Engineering graduates are marginally competent in some of the product realization skills [2]. This is mainly due to the fact many of the concepts listed in the table are introduced late in the curriculum (during senior level courses or at the capstone projects.)

\begin{tabular}{|l|l|}
\hline 1 & Teamwork \\
\hline 2 & Communication \\
\hline 3 & Design for manufacture \\
\hline 4 & CAD systems \\
\hline 5 & Professional ethics \\
\hline 6 & Creative thinking \\
\hline 7 & Design for performance \\
\hline 8 & Design for reliability \\
\hline 9 & Design for safety \\
\hline 10 & Concurrent engineering \\
\hline 11 & Sketching/drawing \\
\hline 12 & Design to cost \\
\hline 13 & Application of statistics \\
\hline 14 & Reliability \\
\hline 15 & Geometric tolerancing \\
\hline 16 & Value engineering \\
\hline 17 & Design reviews \\
\hline 18 & Manufacturing processes \\
\hline 19 & Systems perspective \\
\hline 20 & Design for assembly \\
\hline
\end{tabular}

Table 1. Most Important Product Realization Skills as viewed by industry for a BS level mechanical engineer

Engineering graphics has been a cornerstone of most engineering program. Over the last few years much attention has been focused on the paradigm shift from teaching 2D 
drafting skills to 3D solid modeling. With the advent of 3D solid modeling software such as Mechanical Desktop, Pro/E and Solidworks, more school are integrating this approach into their engineering graphics courses. This is also demanded by industry as documented by ASME study mentioned earlier. Such approach allows incorporating engineering design and its documentation in the first year engineering curriculum.

\section{Revision of Engineering Graphics}

Engineering graphics taught at the City College of New York and Borough of Manhattan Community College is 2-credit 4-contact hour freshman level class. The main thrust of the course has traditionally been 2D design documentation drawing. The original curriculum included topics such as:

- Lettering

- Tools and line symbols

- Geometric construction

- Multiview / pictorial sketching and drawing

- Sectional views and dimensioning

- Auxiliary views

- Working drawings

The class assignments were completed using sketching, instruments, and 2D CAD employing software such as AutoCAD LT or IDEAS. It involved some design project where students produced sketches and drawing of various objects. Solid modeling was introduced toward the end, was covered lightly and was not used in the class projects.

It became apparent that the class does not prepare students for design process and product realization skills demanded in curriculum. The class was modified to address these issues. The revised syllabus includes:

- Sketching

- Solid modeling

- Geometry

- Multiviews and pictorial

- Visualization

- Sectional views

- Auxiliary views

- Constraint-based modeling

- Dimensioning and Tolerances

- Manufacturing processes

- Assemblies

Modifications were designed to incorporate a project-based active learning environment into the class. The project-based component is composed of learning cycles. Each cycle begins with introduction to a concept, followed by physicals exercises (observation) with objects or parts in which the concept is most relevant to promote experiential learning, followed by home work assignments to further promote the concept and culminated by group project where a few of the concepts covered are utilized. 
There are three cycles in a semester. The first one emphasizes sketching and visualization skills. This cycle is finished by a project involving design documentation of solids with simple geometry. The second one emphasizes geometrical construction and multiview projections. This cycle is culminated with projects involving mutiview projection and geometrical construction. The last cycle, which is the longest -typically about six weeks- incorporates all concepts covered in the class. The projects following this cycle involve design documentation of machine parts with complicated geometry. The thrust of projects is to convey how the part is manufactured. The projects are designed to illustrate the relation between the conceptualization of the part, its functionality and its realization. They promote product realization skills such as: teamwork, communication, CAD systems, Creative thinking, Sketching/Drawing, Geometric Tolerancing, Manufacturing Processes and Design for Assembly.

The software employed in the class is Pro/Engineer. It was chosen over AutoCAD mechanical desktop because of its relevance in the industry. Although the learning curve for Pro/E is extremely steep, its powerful command set and portability to other applications in the Pro/Engineering suite justifies its use. Pro/E allows students to manipulate 3D objects. This leads to development of spatial visualization skills, which is a primary objective of engineering graphics class. 3D manipulation reinforces the students analytical geometry skills and provides them an opportunity to practice vector calculus.

Ability to communicate design ideas quickly is a vital skill, specifically among members of a team working on a project. The techniques of sketching are instructed in beginning of class using relatively simple models. However, its usefulness is only appreciated when the students work together in groups. The modified class emphasizes sketching and promotes quick graphics/design communication in a group setting. This kind of exchange takes place among students that are modeling machine parts in their group projects.

In the revised class, geometrical construction need no longer be done with instruments. The software allows students to understand concepts such as tangency, locus of centers in its sketcher mode. We supplement geometrical construction by using actual machine parts where application of these concepts can be observed. Dimensioning activities in the introductory engineering graphics class have focused mainly on documentation drawings. We emphasize tolerances for components that are assembled. It gives students an early start on this practice, which they will be used throughout their education.

A final project in the class consists of modeling all parts in an assembly, putting the parts together in an assembly, and creating detail drawing of parts. Students have to consider modeling strategies for all the parts and how specific parts interact with other parts. A discussion of manufacturing processes and dimensioning constrains are presented in the class. Emphasis is given to the manufacturing processes such as casting, protrusion and mold making. Figures 1, 2 and 3 present typical project conducted for the class. 


\section{Assessment}

The class has been given for two semesters. Students' surveys have indicated that they like the active-learning component. They assess the class to be both a technical one emphasizing the software and a skill class emphasizing solid modeling and product development. They stated the workload is higher than most two-credit classes. However, they realized the competencies acquired in the class would help them throughout their education. They also indicated that they would take similar classes that emphasize group project and active learning. Faculty who teach this class have also responded positively to the new methodology. They feel the new approach allows more depth in coverage of topics and requires students to engage in more self-learning.

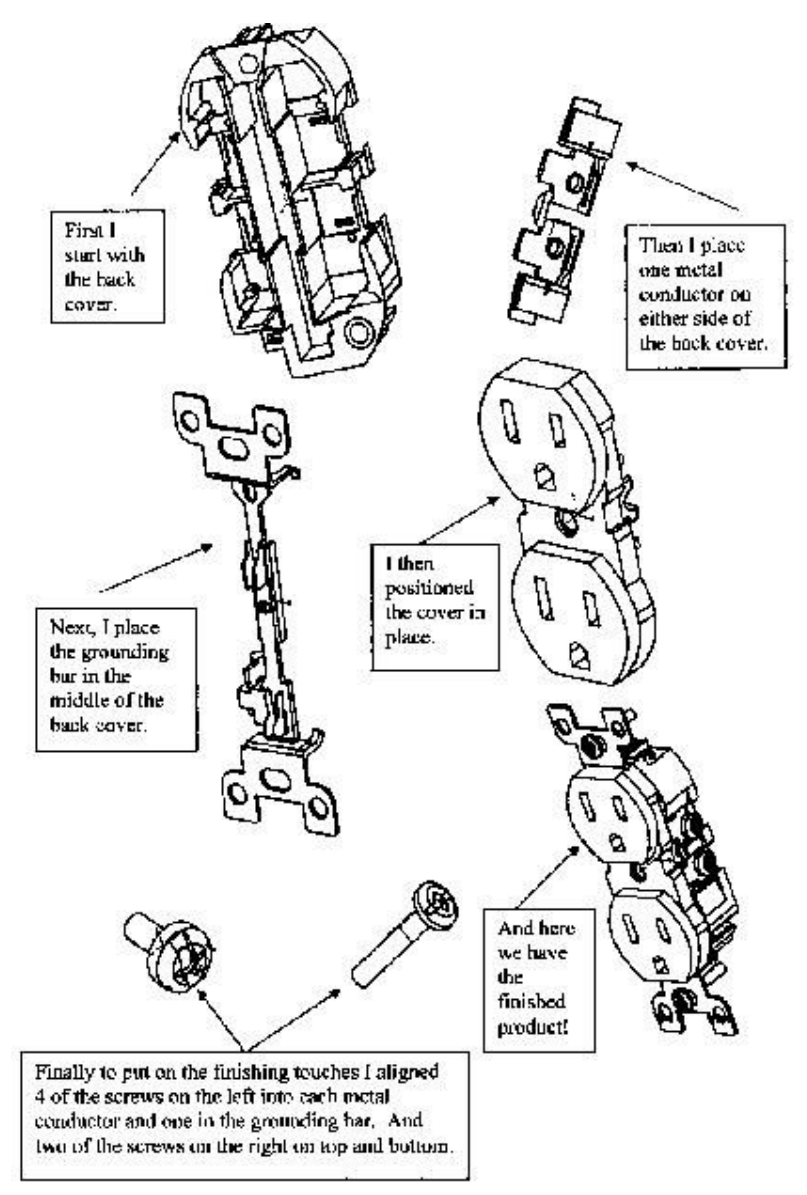

Fig 1. Electric Receptacle Project 

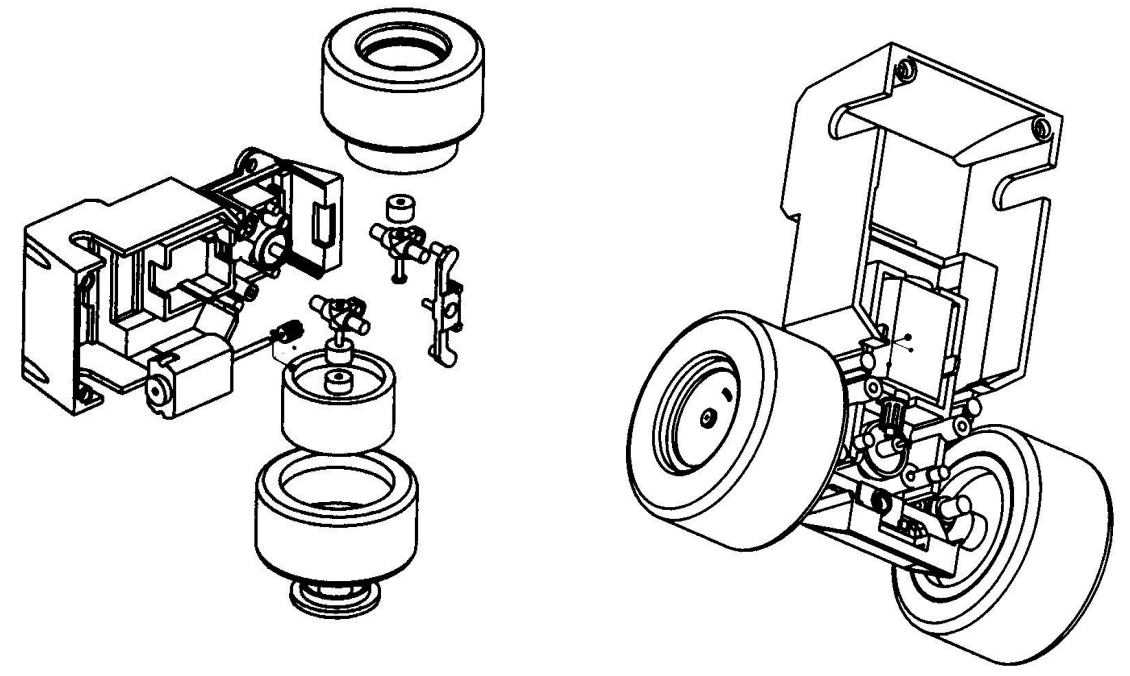

Fig 2. Toy Car Steering Mechanism Project
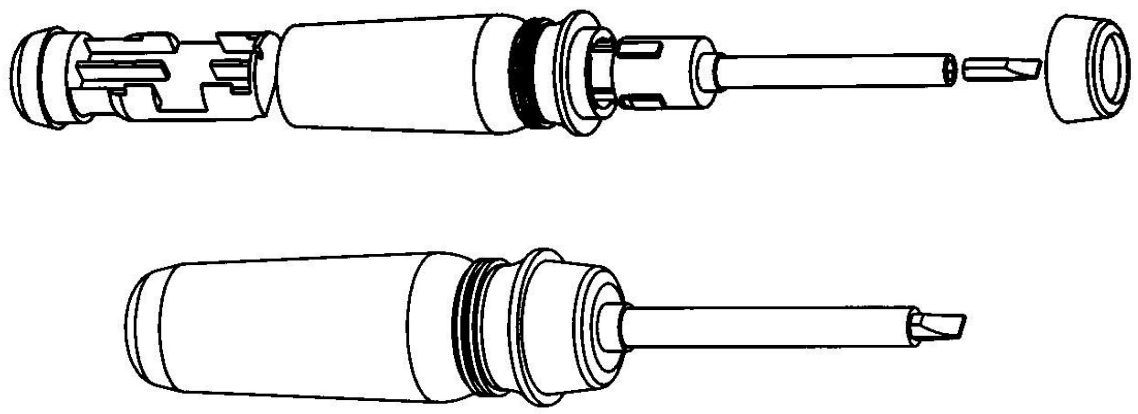

Fig. 3 Screwdriver Project

\section{Acknowledgment}

Financial support for this project has been provided by NSF CCLI grant \#: 0126877.

\section{REFERENCES}

[1] Bahner, B.:" Report: Curricula Need Product Realization”, ASME News, March 1996, v. 15, no 10, pp. 1-6.

[2] Prusak, Z.: "Challenges to future Engineering Professionals- How to Prepare Students to Face Them", Proceedings of ASEE Annual Conference, June 2001. 


\section{Biographies}

Mahmoud K. Ardebili, Ph.D., P.E., is an associate professor and director of Engineering Science program at Borough of Manhattan Community College of City University of New York.

Email: mardebili@bmcc.cuny.edu

Ali M. Sadegh, Ph.D., P.E., former chair of Mechanical Engineering is a professor and director of CAEDD (Center for Advanced Engineering Design and Development) at the City College of City University of New York.

Email: sadegh@me.ccny.cuny.edu 